\title{
Application of Receptive Music Therapy in Internal Medicine and Cardiology
}

\author{
Cyntia Marconato, Eva Cantalejo Munhoz, Marcia Maria Menim, Maria Thereza Albach \\ Curitiba, PR - Brazil
}

\begin{abstract}
Objective - To investigate the effects of receptive music therapy in clinical practice.

Methods - Receptive music therapy was individually applied via musical auditions, including five stages: musical stimulation, sensation, situation, reflection, and behavioral alteration. Following anamnesis and obtainment of consent, patients answered a first questionnaire on health risk evaluation (Q1), and after participating in 16 weekly music therapy sessions, answered a second one (Q2).
\end{abstract}

Results - Two men and 8 women, aged above 18 years, referred to us due to symptoms of stress, emotional suffering, and the need to change lifestyles (health risk behavior) were studied between August 1998 and December 1999. Comparison between answers to $Q 1$ and $Q 2$, showed a trend $(P=0.059)$ for reduction of ingestion of cholesterolrichfoods and for increased prospects in life with a tendency towards improvement, and also of increased intake offiberrich food (55.6\%), increased levels of personal satisfaction $(44.5 \%)$, and decreased levels of stress (66.7\%).

Conclusion - The study demonstrated decreased stress levels and increased personal satisfaction, higher consumption of fiber-rich food, lower cholesterol intake, and a better perspective on life, suggesting that receptive music therapy may be applied in clinical practice as an auxiliary therapeutic intervention for the treatment of behavioral health risks.

Key words: receptive music therapy, behavior alteration, music therapy in cardiology

Faculdade de Artes do Paraná - FAP

Mailing address: Cyntia Marconato - Rua Visconde do Rio Branco, 1335 - S/93/94 - 80420-210 - Curitiba, PR - Brazil - E-mail: cyntiamt@ig.com.br
Music as a "therapeutic instrument " is a modern approach in therapy, not based on an idealistic concept about "the curative capacity of music," but rather on scientific research and techniques. Thus, music does not "cure" effectively by itself; its therapeutic impact results from systematic professional application ${ }^{1-4}$.

The receptive music therapy proposal presented here is based on the holistic concept ${ }^{5}$, which considers the human organism as an integrated whole involving biopsychosocial and spiritual patterns.

The objective of receptive music therapy is to alter patient behavior, aiming at the correction of habits and attitudes that cause health risks in a global way, and in particular in the cardiovascular areas ${ }^{6-8}$.

\section{Methods}

Receptive music therapy was applied in an individualized form in musical auditions according to a specific procedure, which included: 1) musical stimulation - the pieces used belonged to the Renaissance, Baroque, Classical, and Romantic periods, with a predominance of works by Bach, Beethoven, Brahms, Dvorak, Grieg, Hoydn, Josquin des Prés, Mozart, Obrecht, Rachmaninoff, Vivaldi, and Willaert ${ }^{9}$; 2) sensation - a stage of awareness of the emotional and physical sensations perceived during the musical stimulation; 3) situation - the patient identified conditions in daily life in which such sensations occurred more frequently; 4) reflection - the patient pondered the sensations experienced during the session and how or why such sensations were related to certain situations in his or her daily life. This division in 3 stages (sensation, situation, and reflection) is merely didactic, because all 3 may occur simultaneously during each session ${ }^{10}$; 5) alteration in behavior - related to changes in living habits, expected to occur after weeks or months.

The general objective of the study was the evaluation of the effect of this proposal in clinical practice in general and specifically to: a) alter patient behavior by aiming at the correction of habits and attitudes capable of offering ge- 
neral and, in particular, cardiovascular health risks; b) increase patients' internal perception and self-esteem; c) strengthen patients' general structure aiming at a greater sense of emotional equilibrium and assurance; d) favor emotional expression; e) contribute to clarification of internal conflicts; f) permit a positive alteration in the patient's clinical prognosis.

Between August 1998 and December 1999, 10 patients ( 2 men and 8 women) over 18 years of age with symptoms of stress, emotional suffering, and the need to change their daily lifestyles (smoking, sedentariness, obesity and stress) were referred by their attending physician.

Each patient invited to enter the receptive music therapy project received initial explanations about its objectives and procedures. Following musical therapy anamnesis and the signing of a consent form, the patients answered a questionnaire on health risk evaluation (Q1), and following 16 weekly sessions of music therapy filled out a second questionnaire (Q2).

The statistical analysis of results was made using the test of "comparison between two proportions." A statistical level of significance of $5.0 \%(\mathrm{P}<0.05)$ was adopted.

\section{Results}

Five patients maintained the practice of physical exercise; 3 did not initiate any form of exercise; 1 began, and 1 gave up treatment. Three patients experienced increased length and quality of sleep; 4 did not change, and 2 decreased their sleeping periods.

Five increased their global health indexes and 4 maintained theirs.

Seven patients maintained the frequency of consumption of cholesterol-rich food; 5 had been ingesting it rarely, 2 decreased its ingestion, 1 went from a regimen of daily ingestion to one of ingestion 3 or 4 times a week; and 1 who had ingested such food 5 or 6 times a week changed to rarely consuming it.
Six patients maintained their level of professional satisfaction, 2 increased it, and 1 changed from partially satisfied to unsatisfied.

Five patients increased their intake of fiber-rich food and 4 maintained it.

Four patients showed an increased level of personal satisfaction, 3 maintained it, and 2 decreased it.

Six patients had a decreased level of stress, 3 maintained their stress level, 2 considered their stress to be of an average level; 1 maintained a high level of stress.

Six patients improved their evaluation of their life prospects; 1 decreased this evaluation, and 2 maintained their positions of positive life prospects.

Statistical analysis showed limitrophe $(\mathrm{P}=0.059)$ probability for the ingestion of cholesterol-rich food; life prospects had a tendency to increase.

\section{Discussion}

For the final evaluation of patients' health risks, not only answers to the Q2 questionnaire, but the manner in which the subject answered to the second evaluation and his or her situation and life context at that moment were considered.

During receptive music therapy, the patients improved their self-knowledge and inner perception, rendering their analysis relative to health risks more critical. In the second questionnaire, patients started to ponder their emotional reactions, a result which may be considered an alteration in behavior per se.

Absence of specific publications in this area, the number of patients, and the period of the research represent limitations of this study.

In conclusion, the data obtained suggest that receptive music therapy can be applied to patients in clinical and cardiological medical practice as a coadjutor therapeutic intervention for the management of health risk behavior. Further studies may confirm these findings.

\section{References}

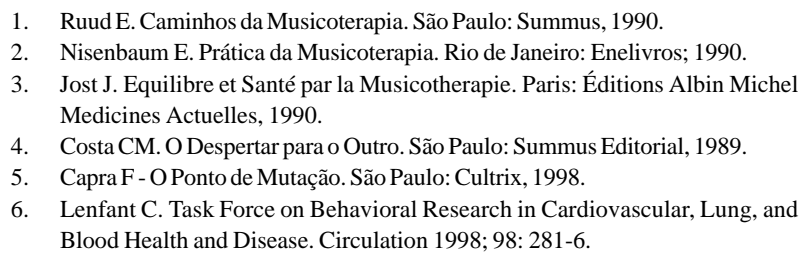

7. Marlatt GA, Gordon JR. Prevenção de Recaída: Estratégias de Manutenção no Tratamento de Comportamentos Adictivos. Porto Alegre: Artes Médicas, 1993.

8. Cordioli AV. Psicoterapias: abordagens atuais. Porto Alegre: Artes Médicas, 1993.

9. Wisnik JM. O Som e o Sentido. Uma Outra História das Músicas. São Paulo: Companhia das Letras, 1999.

10. Miranda CF. Construindo a Relação de Ajuda. Belo Horizonte: Crescer, 1995. 